\title{
AVALIAÇÃO DO PERFIL DE TRABALHADORES E DAS CONDIÇÕES DE TRABALHO EM MARCENARIAS NO MUNICÍPIO DE VIÇOSA-MG ${ }^{1}$
}

\author{
Kátia Regina Silva ${ }^{2}$, Amaury Paulo de Souza ${ }^{3}$ e Luciano José Minetti ${ }^{4}$
}

\begin{abstract}
RESUMO - Esta pesquisa foi desenvolvida nos ambientes de trabalho de marcenarias localizadas no município de Viçosa, Minas Gerais, para realizar o levantamento do perfil dos trabalhadores e das condições de trabalho relacionadas às atividades exercidas em marcenarias, visando a melhoria da saúde, do bem-estar, da segurança, do conforto e da produtividade dos trabalhadores. O levantamento do perfil dos trabalhadores e das condições de trabalho foi realizado por intermédio da aplicação de questionários aos trabalhadores das marcenarias avaliadas e das observações e anotações realizadas durante a coleta dos dados. Pelos resultados obtidos, foram constatados diversos problemas relacionados aos marceneiros, como, por exemplo, cansaço, dores nas pernas e na coluna, alergia devido à utilização de produtos químicos e ao pó da madeira, falta de treinamento para exercer a profissão e praticamente nenhuma noção sobre segurança e higiene no trabalho. A incidência de acidentes relatados foi baixa; as mãos foram as partes mais afetadas por cortes leves, não tendo sido relatado nenhum tipo de acidente grave. Pôde-se constatar também que há necessidade de conscientizar os proprietários das marcenarias sobre a importância e os benefícios da segurança e higiene no trabalho para os seus funcionários.
\end{abstract}

Palavras-chave: Ergonomia, marcenaria, segurança do trabalho e qualidade de vida.

\section{EVALUATION OF WORKERS' PROFILE AND WORK CONDITIONS IN JOINERIES IN VIÇOSA, MINAS GERAIS, BRAZIL}

\begin{abstract}
This work was carried out in joineries located in Viçosa, Minas Gerais, Brazil, to survey the profile of workers and work conditions related to the activities performed, aiming to promote health, welfare, safety, comfort and productivity of the workers. This survey was carried out by means of the application of questionnaires to the workers and from observations made during data collection. According to the obtained results, various problems related to the joiners were observed, such as fatigue, pain in legs and spine, allergies due to the use of chemicals and sawdust, lack of training for the work and almost none knowledge about work safety and sanitation. The incidence of accidents was low, and hands were the parts which were most injured by small cuts. No severe accidents were registered. It is necessary to aware the joinery owners of the importance and benefits of work safety and sanitation for their workers.
\end{abstract}

Key words: Ergonomy, joineries, work safety, life quality.

\section{INTRODUÇÃO}

No segmento de móveis sob encomenda, existe uma multiplicidade de micro e pequenas empresas, em geral marcenarias, cuja matéria-prima básica é a madeira compensada conjugada com madeiras nativas. Seus equipamentos e suas instalações são quase sempre deficientes e ultrapassados, o que gera muitas imprecisões nas medidas, e o trabalho ainda é bastante artesanal. Seu produto final destina-se predominantemente ao mercado doméstico (Gorini, 1998).

1 Recebido para publicação em 29.01.2001.

Aceito para publicação em 3.12.2002.

2 Fontes de auxílio do projeto CNPq e CAPES.

2 Pós-graduanda, Dep. de Engenharia Florestal da Universidade Federal de Viçosa - UFV, 36571-000 Viçosa-MG; ${ }^{3}$ Prof. do Dep. de Engenharia Florestal da UFV; ${ }^{4}$ Pesquisador do Dep. de Engenharia Florestal da UFV. 
Os estudos ergonômicos visam realizar mudanças nas condições e no ambiente de trabalho, aperfeiçoando e adaptando máquinas e equipamentos utilizados na execução das tarefas, de acordo com as características físicas e condições psicológicas do trabalhador, com o objetivo de propiciar-lhe segurança, saúde e conforto e, conseqüentemente, obter maior eficiência no trabalho executado.

A adoção de práticas ergonômicas implica, entre outros, a qualidade de vida no trabalho, o que, segundo Bom Sucesso (1997), é condição essencial para o êxito de uma empresa ou de um empreendimento.

Podem ser citadas ainda como referência à qualidade de vida no trabalho as condições físicas do próprio local de trabalho, como, por exemplo, instalação sanitária adequada, água fresca e filtrada, ambiente adequado para realização de refeições e condições ambientais favoráveis.

A qualidade de vida no trabalho reflete diretamente na vida social e no relacionamento familiar do trabalhador, que pode ser severamente afetado. A qualidade dos produtos fabricados e, ou, dos serviços prestados também é afetada pelas más condições de trabalho, devido ao estresse, ao cansaço e à fadiga provocados por inadequado ambiente de trabalho.

O objetivo deste trabalho foi realizar o levantamento do perfil dos marceneiros e das condições de trabalho relacionadas às atividades exercidas em marcenarias, no município de Viçosa-MG, visando a melhoria da saúde, do bem-estar, da segurança, do conforto, da qualidade de vida e da produtividade dos trabalhadores.

\section{MATERIAL E MÉTODOS}

\subsection{Caracterização do Local de Estudo}

A coleta de dados para o desenvolvimento deste trabalho foi realizada com trabalhadores de marcenarias localizadas em Viçosa-MG, no período de agosto a novembro de 1998.

A jornada de trabalho em todas as marcenarias visitadas tinha duração de 9 horas, no período de segunda à sexta-feira. Na grande maioria, a jornada iniciava às 7 horas, terminando às 17 horas, e o intervalo para almoço tinha duração de 1 hora, entre 11 e 12 horas.

As empresas do setor moveleiro na cidade de Viçosa são, em sua maioria, familiares, onde trabalham o próprio dono como marceneiro e os filhos, como ajudantes.
A fabricação de móveis é caracterizada pela produção sob encomenda. A produção é praticamente artesanal, com auxílio de algumas máquinas utilizadas para agilizar e facilitar o processo de fabricação, e destina-se ao consumo doméstico no próprio município e a outras cidades da região.

As máquinas utilizadas na execução das atividades dentro das marcenarias estão descritas a seguir:

- serra circular: utilizada para serrar madeira, composta de uma lâmina circular dentada;

- desempenadeira: utilizada para desempenar madeira, dotada de um eixo contendo navalhas;

- serra de fita: máquina destinada a recortes externos, retos e curvos, composta de uma lâmina estreita, flexível, dentada e sem fim;

- tupia: utilizada para fazer rebaixos, molduras, ranhuras, perfis, canais, entre outros. As ferramentas de corte utilizadas na tupia são as facas, os discos dentados e as lâminas circulares dentadas;

- desengrossadeira: utilizada para dimensionar a espessura e a largura de peças de madeira, composta por um eixo contendo navalhas;

- lixadeira de fita: utilizada para acabamento de superfícies; e

- furadeira: utilizada para fazer furos e cavas, em peças de madeira, e encaixes de espigas ou cavilhas.

\subsection{População e Amostragem}

O trabalho foi realizado em 17 marcenarias, perfazendo um total de 42 marceneiros entrevistados.

\subsection{Levantamento do Perfil dos Marceneiros}

O perfil dos marceneiros foi levantado por intermédio de um questionário aplicado em forma de entrevista, no próprio local de trabalho dos marceneiros. Com o objetivo de evitar erros na interpretação das perguntas e deixar o entrevistado à vontade para respondê-las, o questionário foi aplicado individualmente por um entrevistador.

Durante a aplicação dos questionários os principais dados levantados foram a satisfação no trabalho, o tempo na função, o tempo na empresa, a idade do primeiro trabalho, o estado civil, o número de filhos e de dependentes, 
a idade, a escolaridade, a origem, os vícios, a lateralidade, o salário e o registro em carteira.

\subsection{Caracterização do Ambiente de Trabalho}

A caracterização do ambiente de trabalho foi realizada por intermédio de questionamentos realizados durante a aplicação dos questionários e por meio de observações no local. As observações, em relação ao ambiente de trabalho, foram feitas com o objetivo de avaliar a higiene do local de trabalho e a presença de riscos à segurança e à saúde do trabalhador.

\section{RESULTADOS E DISCUSSÃO}

\subsection{Caracterização das Empresas}

As marcenarias envolvidas neste trabalho estão classificadas, de acordo com LIMA (1998), como microempresas, possuindo até 15 empregados. As atividades das marcenarias estudadas resumem-se na fabricação de móveis e esquadrias e na reforma de móveis usados.

As empresas possuíam, em média, 2,6 marceneiros e 1,8 ajudante de marceneiro. Em 76,5\% das marcenarias, além dos funcionários, os próprios donos exerciam a atividade de marceneiro, e destas 41,2\% utilizavam também a mão-de-obra familiar, esposa e filhos, nos serviços de marcenaria e escritório. Entre as marcenarias estudadas, apenas $41,2 \%$ possuíam funcionários exclusivos para serviços de escritório, devendo ser ressaltado que nas demais este trabalho era realizado pelo proprietário, pela esposa e, ou, pelos filhos. Para os serviços de limpeza, apenas $11,8 \%$ possuíam funcionários exclusivos; já nas demais marcenarias a limpeza era realizada pelos próprios marceneiros e, ou, ajudantes de marceneiro.

\subsection{Levantamento do Perfil do Marceneiro}

\subsubsection{Características Gerais do Marceneiro}

O conhecimento do perfil dos trabalhadores é de grande importância para o desenvolvimento de trabalhos referentes a treinamentos, orientações e interferências no ambiente de trabalho, entre outros. Em um programa de treinamento, é indispensável a identificação de características do trabalhador, como o grau de escolaridade e a experiência na profissão, que são indicativos para delinear a forma de abordagem dos temas durante o treinamento.
O Quadro 1 apresenta os valores médios de características dos 42 trabalhadores de marcenaria avaliados.

O tempo dos marceneiros na função variou de 2 a 20 anos, sendo 42,8\% deles marceneiros há mais de dez anos. Já o tempo na empresa variou de 1 a 27 anos, e $42,9 \%$ estão na empresa há mais de dez anos. De acordo com os dados encontrados, $54,7 \%$ aprenderam a profissão na empresa em que trabalham, começando como ajudantes de marceneiro, o que justifica ser a média de tempo na empresa maior que o tempo na função.

A faixa etária dos trabalhadores variou de 19 a 67 anos, em que $40,5 \%$ têm entre 30 e 40 anos, sendo $35,7 \%$ abaixo de 30 anos e $23,8 \%$ acima dos 40 anos.

Entre os entrevistados, $88,0 \%$ afirmaram fazer uso de bebidas alcoólicas, do tipo cerveja e cachaça, somente nos fins de semana, feriados e nas datas comemorativas.

Quadro 1 - Características do perfil dos trabalhadores das marcenarias avaliadas

Table 1 -Characteristics of the profile of workers in the evaluated joineries

\begin{tabular}{|c|c|c|c|}
\hline \multicolumn{3}{|c|}{ Variáveis Analisadas } & Valores Médios \\
\hline \multicolumn{3}{|c|}{ Tempo na função } & 9 anos \\
\hline \multicolumn{3}{|c|}{ Tempo na empresa } & 9,6 anos \\
\hline \multicolumn{3}{|c|}{ Idade do $1^{\circ}$ trabalho } & 12 anos \\
\hline Estado civil & $\begin{array}{l}\text { Casado } \\
\text { Amasiado } \\
\text { Solteiro }\end{array}$ & & $\begin{array}{l}71,4 \% \\
4,8 \% \\
23,8 \%\end{array}$ \\
\hline \multicolumn{3}{|c|}{ Número de filhos } & 3 \\
\hline \multicolumn{3}{|c|}{ Número de dependentes } & 4 \\
\hline \multicolumn{3}{|c|}{ Idade } & 33,8 anos \\
\hline \multirow{3}{*}{ Escolaridade } & Primário & $\begin{array}{l}\text { Completo } \\
\text { Incompleto }\end{array}$ & $\begin{array}{l}52,4 \% \\
21,4 \%\end{array}$ \\
\hline & $1^{\circ}$ grau & $\begin{array}{l}\text { Completo } \\
\text { Incompleto }\end{array}$ & $\begin{array}{l}7,2 \% \\
7,1 \%\end{array}$ \\
\hline & $2^{\underline{0}}$ grau & $\begin{array}{l}\text { Completo } \\
\text { Incompleto }\end{array}$ & $\begin{array}{l}2,4 \% \\
9,5 \%\end{array}$ \\
\hline Origem & \multicolumn{2}{|l|}{$\begin{array}{l}\text { Rural } \\
\text { Urbana }\end{array}$} & $\begin{array}{l}21,4 \% \\
78,6 \%\end{array}$ \\
\hline \multicolumn{3}{|l|}{ Casa própria } & $64,3 \%$ \\
\hline Vícios & \multicolumn{2}{|c|}{$\begin{array}{l}\text { Fumo } \\
\text { Bebida alcoólica } \\
\text { Jogos de azar }\end{array}$} & $\begin{array}{l}40,5 \% \\
88,0 \% \\
4,8 \%\end{array}$ \\
\hline Lateralidade & \multicolumn{2}{|l|}{ Destro } & $\begin{array}{l}92,9 \% \\
7,1 \%\end{array}$ \\
\hline \multicolumn{3}{|l|}{ Salário } & 2,5 salários mínimos \\
\hline \multicolumn{3}{|c|}{ Registro em carteira } & $85,7 \%$ \\
\hline
\end{tabular}


De acordo com os dados levantados, apenas 2,4\% possuem renda complementar à média dos 2,5 salários mínimos recebidos, equivalentes a $\mathrm{R} \$ 325,00$ (U\$ 166.70).

Entre os marceneiros entrevistados não foram encontrados analfabetos.

Os marceneiros eram predominantemente destros $(92,9 \%)$, e apenas $7,1 \%$ eram canhotos. Não foram encontrados marceneiros ambidestros.

A maioria dos marceneiros $(85,7 \%)$ possuía registro em carteira de trabalho; os não-registrados em carteira $(14,3 \%)$ trabalhavam de empreitada para as marcenarias que recebiam encomendas extras.

\subsubsection{Satisfação no Trabalho}

A satisfação no trabalho é de extrema importância, quando o objetivo é introduzir inovações, para obter maior qualidade do produto final e melhores condições de trabalho, pois permite melhor aceitação em relação às mudanças.

Grande parte dos marceneiros, 52,4\%, escolheu a profissão por influência dos pais ou familiares próximos; $40,5 \%$ por oportunidade de emprego; e 7,1 , por outros motivos.

Quanto à satisfação no trabalho, 80,9\% mostraramse satisfeitos e não gostariam de mudar de profissão. No entanto, 19,1\%, apesar de estarem satisfeitos com o trabalho, gostariam de mudar para profissões menos cansativas.

\subsubsection{Atividades Diárias}

Os marceneiros exercem várias atividades durante o processo de fabricação de móveis, havendo opiniões diversificadas a respeito da preferência por atividades desenvolvidas e por máquinas utilizadas.

A Figura 1 mostra a preferência dos marceneiros pelas atividades diárias exercidas: montar móveis; lixar utilizando a lixadeira; lixar manualmente; moldar a madeira utilizando a tupia; serrar utilizando a serra de fita; furar utilizando a furadeira; serrar utilizando a serra circular; e desempenar utilizando a desempenadeira.

A atividade de lixar utilizando a lixadeira, considerada de maior facilidade pela maioria dos marceneiros $(59,5 \%)$, também foi classificada como a menos perigosa por grande parte dos marceneiros $(50,0 \%)$. Já a atividade de moldar a madeira utilizando a tupia foi considerada pela maioria como a mais perigosa $(73,8 \%)$ e também a de maior dificuldade $(61,9 \%)$.

A classificação da preferência dos marceneiros por determinadas atividades desenvolvidas pode ser utilizada como instrumento de organização do trabalho, no sentido de promover, dentro do possível, uma rotatividade das tarefas de acordo a preferência de cada um, e com isso obter uma maior satisfação no trabalho e maior rendimento das atividades. A classificação preferencial pode ser utilizada, também, como instrumento na identificação das atividades que oferecem maior risco de acidentes, com o objetivo de evitar ou reduzir estes riscos.

\subsubsection{Saúde}

Os principais problemas referentes à saúde, relatados pelos trabalhadores, foram os relacionados à alergia, em que 54,8\% dos entrevistados reclamaram de alergia ao pó da madeira liberado durante o desdobro, causando irritação na pele e nos olhos, sendo as espécies responsáveis pelas alergias o ipê-preto (Tabebuia impetiginosa (Mart.) Standl.) e o angelim-amargoso (Andira anthelmia (Vell.) Macbr.).

Uma fração dos marceneiros mencionou possuir alergia aos produtos químicos utilizados, como a cola para fórmica $(9,52 \%)$ e o solvente thinner $(7,1 \%)$, que provocavam dores de cabeça. O uso do solvente causava também, segundo os marceneiros, inchaço nos ombros.

Outro problema relatado foi a dificuldade respiratória, geralmente durante a noite, que afeta $21,4 \%$ dos trabalhadores, que julgavam ser devido à inalação de poeira durante a jornada de trabalho.

Uma minoria $(7,14 \%)$ afirmou possuir dores esporádicas na coluna e na articulação entre o ombro e o braço, provocadas, neste caso, pelo aparafusamento de dobradiças, geralmente das portas de guarda-roupas e armários em geral.

\subsubsection{Pausas no Trabalho}

Os marceneiros possuíam horário de pausas programadas, porém não havia rigidez por parte das empresas quanto ao horário e ao tempo de parada. Os intervalos para as pausas, geralmente às 9 horas pela manhã e às 15 horas pela tarde, variavam de 10 a 15 minutos, período em que eram realizados os lanches oferecidos pelos empregadores. 

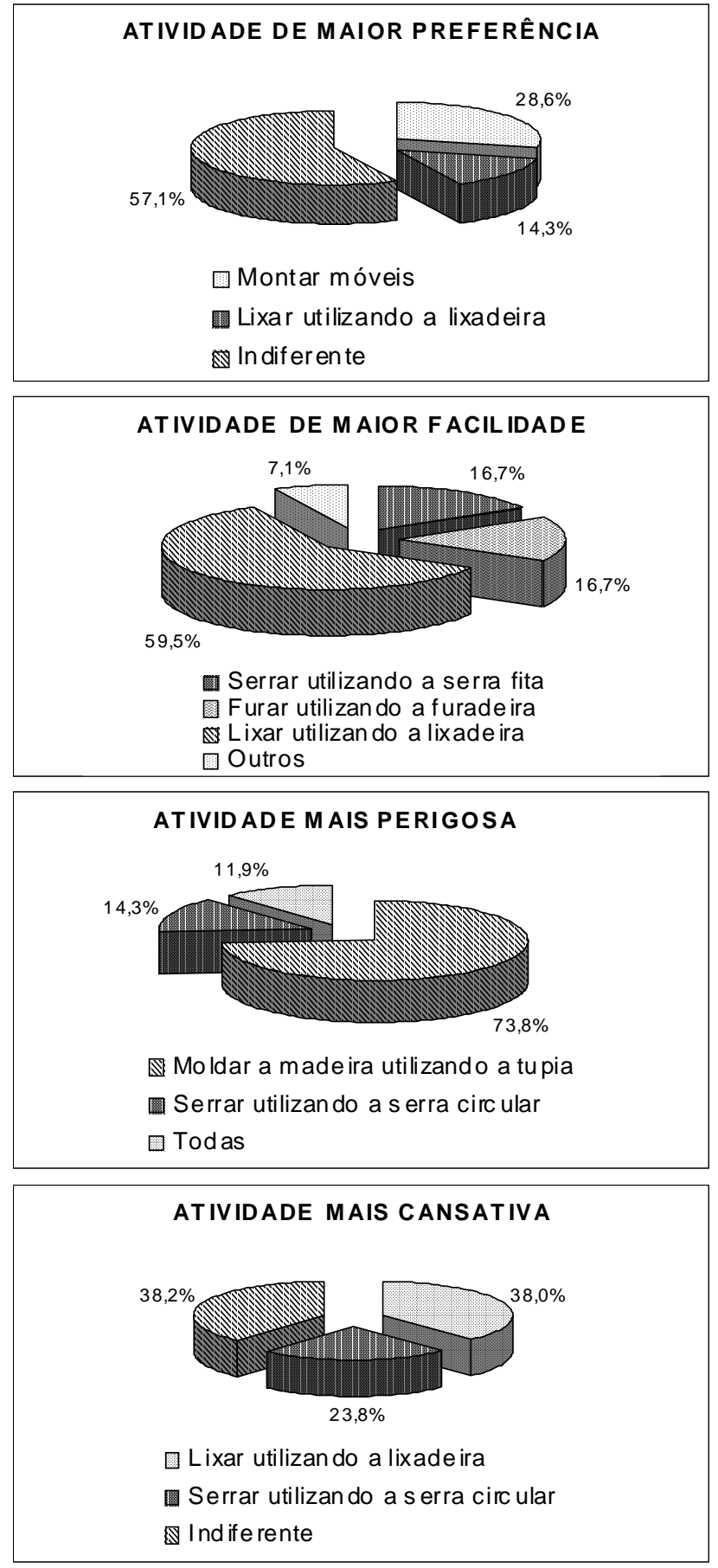
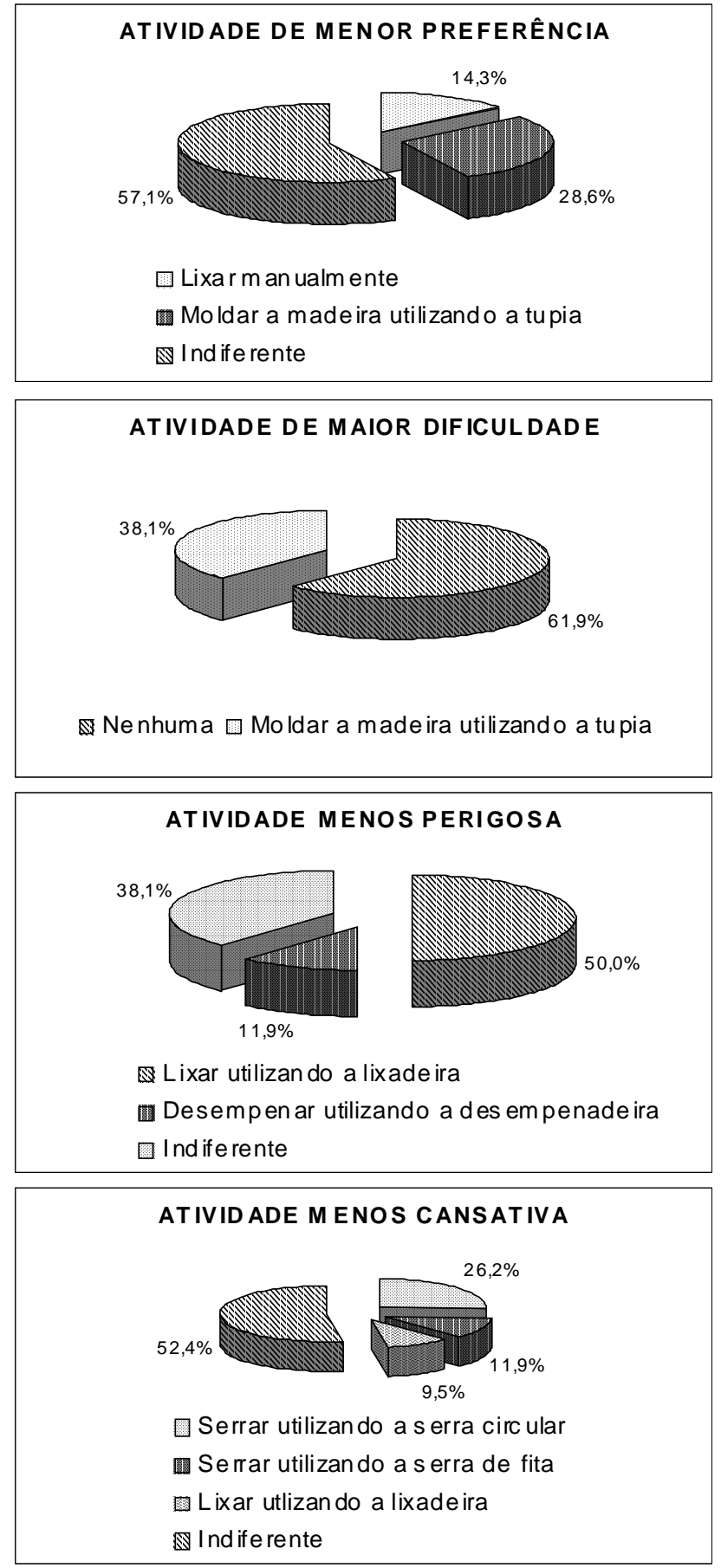

Figura 1 - Classificação preferencial das atividades de fabricação de móveis, de acordo com a opinião dos marceneiros. Figure 1 - Preferential classification of the activities of furniture manufacturing, according to the joiners' opinion. 


\subsubsection{Horário de Trabalho e Horas de Sono}

A jornada de trabalho nas marcenarias estudadas tinha duração de 9 horas, no período de segunda à sextafeira, incluindo 15 minutos para o lanche no período da manhã e da tarde. Na maioria, a jornada de trabalho tinha início às 7 horas e término às 17 horas; o intervalo para almoço tinha duração de 1 hora, no período de 11 a 12 horas.

Todos os marceneiros entrevistados estavam satisfeitos com o horário de trabalho e, se tivessem a oportunidade, não alterariam o horário.

O trabalhador de marcenaria dorme, em média, 7,3 horas por dia, e todos afirmaram ser suficiente o período de sono, por já estarem habituados.

\subsubsection{Treinamento}

Nenhum marceneiro recebeu treinamento externo para exercer a atividade, uma vez que todos aprenderam a profissão dentro da própria marcenaria, iniciando o trabalho como ajudantes de marceneiro.

A grande maioria das marcenarias $(94,1 \%)$ nunca ofereceu cursos sobre segurança no trabalho aos seus funcionários, por estes terem altos custos ou por não terem conhecimento de órgãos que ministrem cursos a respeito deste assunto. Todavia, demonstraram interesse em oferecê-los, caso os cursos fossem gratuitos.

As empresas foram unânimes ao afirmar que nunca ofereceram cursos de reciclagem por não haver necessidade, pois seus funcionários já tinham boa prática no exercício da profissão.

Quanto ao interesse por parte dos marceneiros em relação aos cursos de reciclagem, 66,7\% afirmaram ter interesse em realizar cursos para aperfeiçoar as técnicas de marcenaria, e destes apenas $28,5 \%$ demonstraram interesse em realizar também cursos sobre segurança e higiene no trabalho, e 33,3\% não demonstraram interesse na realização de cursos e reciclagens.

\subsubsection{Higiene e Segurança no Trabalho}

A Portaria 3.214, do Ministério do Trabalho, através da Norma Regulamentadora - NR 24 dos Manuais de SEGURANÇA E MEDICINA DO TRABALHO (1998), prescreve que as instalações sanitárias devem ser submetidas ao processo permanente de higienização, para que sejam mantidas limpas e desprovidas de quaisquer odores durante toda a jornada de trabalho.

No entanto, os sanitários eram mantidos limpos em apenas 23,5\% das marcenarias avaliadas. Nas 76,5\% restantes, os banheiros não eram limpos periodicamente, exalando odores desagradáveis e estando em péssimas condições de uso. Todos os sanitários possuíam lavatórios, porém não eram fornecidas toalhas para a secagem das mãos. Ainda assim, 73,8\% dos funcionários consideraram as condições sanitárias adequadas, constatando a falta de noções sobre higiene por parte dos trabalhadores dessa área.

Em relação ao fornecimento de água, todas as marcenarias avaliadas forneciam água filtrada aos funcionários.

Os resíduos da marcenaria, em sua grande maioria composta pela serragem da madeira, eram acondicionados por $82,3 \%$ das marcenarias dentro dos próprios galpões de trabalho, trazendo sérios riscos de incêndios, principalmente quando se considera o fato de $40,4 \%$ dos marceneiros fazerem uso do fumo, inclusive durante o trabalho, colocando em risco a segurança dos trabalhadores e da própria vizinhança das marcenarias.

No que se refere à segurança no trabalho, apenas $5,8 \%$ das empresas não possuíam equipamentos de proteção individual, por não acharem necessário, e 94,2\% possuíam um equipamento de proteção individual para cada funcionário.

Os equipamentos de proteção individual (EPIs) eram utilizados durante toda a jornada de trabalho por apenas $11,9 \%$ dos marceneiros; $30,9 \%$ utilizavam o protetor auricular e a máscara apenas quando estavam trabalhando em uma máquina; $54,8 \%$ utilizavam os equipamentos de proteção apenas quando se lembravam, e não consideravam necessário o seu uso; e 2,4\% não utilizavam nenhum equipamento de segurança.

O protetor auricular foi considerado pela maioria dos marceneiros ( 92,8\%) como o maior causador de incômodos, por apertar e esquentar a parte externa em torno do ouvido. Os mesmos marceneiros consideraram a máscara como o segundo EPI a causar mais incômodo, por atrapalhar na respiração. Para 7,2\% dos marceneiros, o uso dos equipamentos de proteção individual não causava incômodo. 
As partes do corpo geralmente atingidas durante um acidente dentro de uma marcenaria são as mãos e os dedos. Entre os entrevistados, 78,6\% já se acidentaram com cortes nas mãos e nos dedos, dos quais apenas $9,0 \%$ tiveram cortes mais profundos, com afastamento médio de sete dias, e 7,1\% relataram ter presenciado acidentes que provocaram mutilações de dedos e mãos de companheiros que foram afastados por incapacidade de voltar a trabalhar. A queda de móveis ou tábuas nos pés foi responsável por lesões, nesta parte do corpo, em 4,8\% dos trabalhadores.

As atividades responsáveis pelos acidentes que envolvem cortes são as exercidas na desempenadeira, na tupia e na serra circular. Todos os acidentados afirmaram que a causa dos acidentes foi por descuido.

A tupia foi considerada a máquina mais perigosa por $73,8 \%$ dos marceneiros, e $11,9 \%$ consideraram todas as máquinas perigosas.

A maioria dos marceneiros entrevistados $(97,6 \%)$ não considerou o trabalho de marceneiro perigoso, embora já tenha se acidentado durante o trabalho.

\section{CONCLUSÕES}

Constatou-se, por intermédio dos resultados encontrados, que o trabalho na maioria das marcenarias do município de Viçosa-MG é realizado sob condições adversas à segurança e à saúde dos trabalhadores. A falta de treinamento e, principalmente, de conscientização dos marceneiros e proprietários a respeito de segurança e saúde é o primeiro problema a ser sanado, para que se possa conciliar produtividade e bem-estar no trabalho, beneficiando as principais partes interessadas, ou seja empregado e empregador.

As principais conclusões específicas foram: a) a profissão de marceneiro, apesar de cansativa e de oferecer riscos à saúde e à segurança do trabalhador, foi considerada satisfatória pela maioria $(80,9 \%)$;

b) o trabalho causa aos marceneiros dores nas pernas $(21,4 \%)$, nos braços $(14,2 \%)$, braços e nas pernas $(11,9 \%)$, nos pés $(9,5 \%)$ e na coluna $(21,4 \%)$, por ser realizado na posição em pé durante a jornada de trabalho;

c) os marceneiros necessitam de cursos de treinamento relacionados à área de segurança e higiene no trabalho;

d) os proprietários das marcenarias necessitam ser conscientizados sobre a importância e os benefícios da segurança e higiene no trabalho para os seus funcionários; e

e) a incidência de acidentes relatados, com afastamento médio de sete dias, foi baixa $(9,0 \%)$; as mãos foram as partes mais afetadas por cortes leves $(78,6 \%)$, não tendo sido relatado nenhum tipo de acidente grave que tivesse causado incapacidade permanente de trabalho.

\section{REFERÊNCIA BIBLIOGRÁFICAS}

BOM SUCESSO, E. P. Trabalho e qualidade de vida. Rio de Janeiro: Qualitymark/Dunya, 1997. 183 p.

GORINI, A. P. F. Panorama do setor moveleiro no Brasil, com ênfase na competitividade externa a partir do desenvolvimento da cadeia industrial de produtos sólidos de madeira. Brasília: BNDES, 1998. 47 p.

LIMA, E. S. Novos rumos e desafios da indústria moveleira. In: SEMINÁRIO INTERNACIONAL SOBRE PRODUTOS SÓLIDOS DE MADEIRA DE ALTA TECNOLOGIA 1., 1998, Belo Horizonte. Anais... Viçosa: SIF/UFV, 1998. p. 65-68.

SEGURANÇA e medicina do trabalho. 39.ed. São Paulo: Atlas, 1998. 584 p. v. 16. (Manuais de Legislação Atlas). 